\title{
Produtividade, composição química e características agronômicas de diferentes forrageiras
}

\section{Leandro Barbosa de Oliveira ${ }^{1}$, Aureliano José Vieira Pires ${ }^{2}$, Anselmo Eloi Silveira Viana ${ }^{3}$, Sylvana Naomi Matsumoto ${ }^{3}$, Gleidson Giordano Pinto de Carvalho ${ }^{4}$, Leandro Sampaio Oliveira Ribeiro 5}

\footnotetext{
${ }^{1}$ Mestrando em Agronomia, UESB, Vitória da Conquista, BA.

2 DTRA/UESB, Itapetinga, BA, Pesquisador do CNPq

${ }^{3}$ DFZIUESB, Vitória da Conquista, BA.

${ }^{4} D P A / U F B A$, Salvador, BA.

${ }^{5}$ Mestrando em Zootecnia, UESB, Itapetinga, BA.
}

RESUMO - Um experimento foi realizado com o objetivo de avaliar a produção e extração de nutrientes de diferentes forrageiras. Foram implantadas quatro culturas anuais: milho, sorgo-sudão, sorgo forrageiro e girassol em um delineamento experimental em blocos ao acaso, com quatro tratamentos (culturas) e cinco repetições. O girassol e o sorgo-sudão apresentaram as maiores produções de matéria verde, enquanto o milho e o sorgo forrageiro destacaram-se pela produção de matéria seca. Os maiores valores da fração fibrosa foram observados para o sorgo-sudão. A cultura de girassol extraiu a maior quantidade de cálcio, potássio e magnésio, enquanto o sorgo-sudão apresentou a maior extração de fósforo. A extração de nitrogênio e sódio não diferiu entre as culturas. O milho apresenta-se como melhor forragem para silagem por possuir maior proporção de espiga em relação ao restante da planta.

Palavras-chave: girassol, milho, sorgo, valor nutritivo

\section{Productivity, chemical composition and agronomic characteristics of different forages}

\begin{abstract}
The objective of this work was to evaluate nutrient production and extraction of different forages. Four crops were implanted: corn, Sudan sorghum, forage sorghum and sunflower in an experimental design in randomized blocks, with four treatments and five repetitions. Sunflower and Sudan sorghum had the highest green matter production, while corn and sorghum forages excelled over the other crops for dry matter production. The highest values of fibrous fraction were observed for Sudam sorghum. Sunflower crop extracted the highest amount of calcium, potassium and magnesium, while Sudan sorghum showed the highest phosphorus extraction. Extraction of nitrogen and sodium was not different among crops. Corn is the best forage for silage because it has the highest ear proportion in relation to the rest of the plant.
\end{abstract}

Key Words: corn, nutritional value, sorghum, sunflower

\section{Introdução}

As regiões tropicais caracterizam-se pelo elevado número de espécies forrageiras com grande potencial para utilização na alimentação de ruminantes. O milho, o sorgo e o girassol são forrageiras muito utilizadas pelos pecuaristas, tendo em vista a alta capacidade produtiva dessas espécies e elevado valor nutritivo.

Entre os fatores que influenciam as concentrações dos nutrientes nas forrageiras, destacam-se a espécie, a origem, as condições de cultivo, as condições ambientais durante o crescimento, a maturidade, a relação folha/colmo, o nível de inserção (topo ou base da planta) da fração amostrada e as características estruturais da parede celular (Queiroz et al., 2000).

O milho (Zea mays) é uma planta muito utilizada como forragem na alimentação animal e também uma das melhores plantas para ensilar, pois, no momento propício ao corte, possui quantidade suficiente de carboidratos e quantidades elevadas de massa seca para boa fermentação e, cujo valor nutricional é superior ao das demais silagens (Lempp et al., 2000), resultando em alimento de ótima qualidade e de boa aceitação pelos animais.

O sorgo (Sorghum bicolor), originário do centro da África e parte da Ásia, é uma espécie do tipo C4, de dia curto e com altas taxas fotossintéticas (Magalhães et al., 2003). A 
planta do sorgo, por se adaptar a uma variedade de ambientes e produzir razoavelmente bem sob condições desfavoráveis (Magalhães et al., 2000), tem se tornado uma alternativa para alimentação animal, especialmente em regiões de baixa disponibilidade de água. A espécie possui tolerância à seca, produz sementes ricas em proteínas, vitaminas, carboidratos e sais minerais e plantas com elevado volume de massa verde (Carvalho et al., 2000).

O sorgo forrageiro é uma das plantas mais indicadas para produção de silagem, por apresentar elevado rendimento e características que favorecem o perfil de fermentação desejável, como adequados teores de matéria seca e de substratos fermentescíveis, além de baixo poder tampão (Fernandes et al., 2009).

O girassol (Helianthus annuus) apresenta características agronômicas importantes, como ciclo curto e maior tolerância à seca, ao frio e ao calor, em comparação à maioria das espécies cultivadas no Brasil (Leite, 2005). É uma cultura com grande capacidade de produção de matéria seca e acúmulo de nutrientes, possui sistema radicular profundo, favorece a rápida ciclagem de nutrientes ao longo do perfil de solo e possibilita melhor desenvolvimento das culturas subsequentes (Castro et al., 2005).

Objetivou-se com este trabalho avaliar as características agronômicas, a extração de nutrientes e a composição bromatológica das culturas do milho, sorgo-sudão, sorgo forrageiro e girassol.

\section{Material e Métodos}

O experimento foi realizado em área do Setor de Forragicultura e Pastagem da Universidade Estadual do Sudoeste da Bahia, localizada na cidade de Itapetinga, Bahia, pertencente à Mesorregião Centro-Sul Baiano, com altitude de $279 \mathrm{~m}$, latitude $15,25^{\circ}$ Sul e $40,25^{\circ}$ de longitude oeste. O delineamento experimental foi de blocos casualizados, com quatro tratamentos (culturas): milho (Ag 5011), sorgo-sudão, sorgo forrageiro (BR 601) e girassol (Rumbsol 91) e cinco repetições.

Amostras do solo da área foram coletadas na camada de 0 a $20 \mathrm{~cm}$ e analisadas. Na análise, foram obtidos os seguintes valores: argila, 16\%; pH, 5,7; fósforo, 42 ppm; potássio, $0,38 \mathrm{cmol}_{c} / \mathrm{dm}^{3}$; cálcio, $3,2 \mathrm{cmol}_{\mathrm{c}} / \mathrm{dm}^{3}$; magnésio, $1,3 \mathrm{cmol}_{\mathrm{c}} / \mathrm{dm}^{3}$; alumínio, $0,0 \mathrm{cmol}_{\mathrm{c}} / \mathrm{dm}^{3} ; \mathrm{H}, 2,0 \mathrm{cmol}_{\mathrm{c}} / \mathrm{dm}^{3}$; soma das bases, $4,9 \mathrm{cmol}_{\mathrm{c}} / \mathrm{dm}^{3}$; capacidade de troca catiônica, $6,9 \mathrm{cmol}_{\mathrm{c}} / \mathrm{dm}^{3}$; saturação por bases, $71 \%$. A precipitação total durante os meses de condução do experimento foi de $320 \mathrm{~mm}$

Para a implantação das culturas foram realizadas uma aração e duas gradagens no preparo do solo. A área foi dividida em parcelas medindo 5,0 $\mathrm{m}$ de comprimento e 2,0 $\mathrm{m}$ de largura e o espaçamento entre linhas foi de $0,70 \mathrm{~m}$, totalizando seis fileiras. A semeadura foi realizada de forma manual no dia 21/10/2006, com desbaste visando obter densidade de $60.000,140.000,140.000$ e 60.000 plantas/ha para o milho, o sorgo-sudão, o sorgo forrageiro e o girassol, respectivamente, e adubação de acordo com as recomendações da quinta aproximação da Comissão de Fertilidade do Solo de Minas Gerais (CFSMG, 1999).

O corte de cada forrageira foi realizado quando as plantas apresentaram-se em condições ideais para serem ensiladas. Foram coletadas cinco plantas representativas de cada parcela para avaliação e separação dos componentes estruturais: colmo, folhas e espiga/panícula/capítulo. Foram feitas as pré-secagens das amostras de cada parte da planta, depois de pré-secas a $60^{\circ} \mathrm{C}$, e levadas em estufa com circulação de ar forçada a $105^{\circ} \mathrm{C}$ por 24 horas para obtenção da matéria seca.

As plantas das duas fileiras centrais de cada parcela foram cortadas a $10 \mathrm{~cm}$ de altura do solo e utilizadas para determinação da produção de matéria verde e de matéria seca. Imediatamente após o corte, as forragens foram picadas em partículas com tamanho médio de dois centímetros e colocadas em sacos plásticos vedados e congeladas $\left(-10^{\circ} \mathrm{C}\right)$ para posteriores determinações laboratoriais.

Após pré-secagem, as amostras foram trituradas em moinho tipo Willey, em peneiras com crivos de $1 \mathrm{~mm}$ e em seguida foram analisadas para determinação da composição em matéria seca (MS), nitrogênio total (NT), fibra em detergente neutro (FDN), fibra em detergente ácido (FDA), celulose, hemicelulose, lignina, extrato etéreo (EE), nitrogênio insolúvel em detergente neutro (NIDN) e nitrogênio insolúvel em detergente ácido (NIDA), conforme procedimentos descritos por Silva \& Queiroz (2002). A solução mineral para determinação dos macroelementos minerais foi preparada por via úmida. Após as devidas diluições, o teor de fósforo foi determinado por colorimetria; os de cálcio e magnésio, em espectrofotômetro de absorção atômica e o de sódio e potássio, em espectrofotômetro de chama, também segundo procedimentos descritos por Silva \& Queiroz (2002). Estimaram-se os valores de nutrientes digestíveis totais (NDT) segundo Cappelle et al. (2001).

Os dados foram analisados por meio de análise de variância e pelo teste Tukey a 5\% de probabilidade utilizando-se o programa SAEG, versão 8.1 (Ribeiro Jr., 2001).

\section{Resultados e Discussão}

O número de dias para colheita foi de 69 dias para o sorgo forrageiro, 75 dias para o sorgo-sudão e 77 dias para o milho e para o girassol. Os ciclos das culturas do milho, 
do sorgo e do girassol podem variar de acordo com as condições de ambiente a que forem submetidas (clima, solo, manejo, etc). Conhecer essa variação é importante, pois permite o planejamento da colheita e o uso dos implementos da propriedade.

A produção de matéria verde variou $(\mathrm{P}<0,05)$ entre as culturas (Tabela 1) e foi maior para o girassol e o sorgo forrageiro, 83,9 e 82 t de MV/ha, respectivamente, diferindo do milho e do sorgo-sudão que tiveram menor produtividade.

Os resultados encontrados neste trabalho, para todas as culturas estudadas, foram superiores aos valores médios encontrados por Mello et al. (2004) na época de safra no Rio Grande do Sul. Esses autores obtiveram produções médias de 20,78; 18,40 e 16,34 t MV/ha para cultivares de milho, sorgo e girassol, respectivamente, e provavelmente estão relacionados às condições favoráveis de clima e solos, que contribuíram para a alta produtividade alcançada pelas culturas.

A cultura de girassol apresentou a menor produção de MS, diferindo $(\mathrm{P}<0,05)$ estatiscamente do milho e do sorgo forrageiro, que apresentaram as maiores produções (Tabela 1). As produtividades obtidas com as culturas do milho e do sorgo forrageiro podem ser consideradas muito boas, tendose em conta a região sudoeste da Bahia. Esses resultados foram superiores aos obtidos por outros autores, que observaram valores de produtividade de MS variando de 8,0 a 23,0 t/ha para a cultura do milho (Fonseca et al., 2002; Vasconcelos et al., 2005) e de 8,8 a 16,6 t/ha para o sorgo (Neumann et al., 2002; Resende et al., 2003). Já na cultura do girassol a produtividade da MS foi um pouco menor se comparada à obtida por Mello et al. (2006), que observaram variação de 23,2 a 39,2\% de MS. Menor produtividade de MS do girassol em comparação às culturas de sorgo e milho também foram encontradas por Henrique \& Andrade (1997) na época da safrinha em São Paulo, com produções de MS em torno de 8,5 t/ha para o milho, 8,0 t/ha para o sorgo e 5,6 t/ha para o girassol.

Ressalta-se que, no período do experimento, houve alta precipitação e isso fez com que a cultura do milho apresentasse produção de MS por área igual à dos sorgos forrageiro e sudão, culturas essas mais tolerantes a déficit hídrico que o milho, ao passo que, se as condições hídricas não fossem favoráveis, o milho tenderia ter produção de MS por área menor em relação aos sorgos.

Quanto menor a participação das frações colmo e folhas, maior a fração das espigas ou panículas, o que pode proporcionar melhor valor nutritivo na silagem. A cultura do milho apresentou maior $(\mathrm{P}<0,05)$ participação de espiga na MS comparando com a proporção de panícula do sorgo e capítulo do girassol (Tabela 1). Já Villela et al. (2003) trabalhando com a cultura do milho verificaram variação de 66,18 a 69,19\% na participação de espigas na MS, valores esses superiores aos encontrados neste trabalho. As maiores proporções das frações colmo na MS foram encontradas nas cultivares de sorgo forrageiro e sorgo-sudão que resultaram numa menor proporção de panículas e grãos na MS, quando comparados ao milho e ao girassol, que por sua vez apresentaram maior participação de folha na MS. Von Pinho et al. (2006) encontraram proporções de colmo na MS da planta em cultivares de sorgos variando de 16,7 a $49,5 \%$, valores inferiores ao relatado neste trabalho.

Analisando-se a contribuição dos componentes estruturais da planta (Tabela 2) houve diferença $(\mathrm{P}<0,05)$ entre culturas, sendo que o milho mostrou maior contribuição de espiga e menor de colmo juntamente com o girassol, já o sorgo-sudão e o sorgo forrageiro apresentaram maiores frações de colmo e menores de panícula, o girassol maior proporção de folha, essa mesma tendência foi encontrada por Mello et al. (2004) na época de safra no Rio Grande do Sul.

Tabela 1 - Produções de matéria verde e matéria seca de culturas forrageiras colhidas no ponto de ensilagem

\begin{tabular}{|c|c|c|c|c|c|c|}
\hline Produção (kg/ha) & Milho & Sorgo-sudão & Sorgo forrageiro & Girassol & Média & CV $(\%)$ \\
\hline Matéria verde total & $67.180 \mathrm{~b}$ & $66.480 \mathrm{~b}$ & $82.000 \mathrm{a}$ & $83.900 \mathrm{a}$ & 74.890 & 10,4 \\
\hline Matéria seca total & $21.010 \mathrm{a}$ & 19.613ab & $23.145 \mathrm{a}$ & $15.952 b$ & 19.927 & 13,4 \\
\hline Matéria seca de espiga, ou panícula ou capítulo & $9.707 a$ & $3.664 \mathrm{bc}$ & $1.584 \mathrm{c}$ & $5.734 b$ & 5.173 & 29,5 \\
\hline Matéria seca de folhas & $3.275 \mathrm{ab}$ & $2.178 b$ & $2.484 \mathrm{ab}$ & $3.889 a$ & 2.959 & 32,0 \\
\hline Matéria seca de colmos & $7.896 \mathrm{c}$ & $13.741 \mathrm{~b}$ & $18.651 \mathrm{a}$ & $6.404 \mathrm{c}$ & 11.673 & 22,6 \\
\hline
\end{tabular}

Médias seguidas pela mesma letra na mesma linha não diferem entre si pelo teste Tukey a 5\% de probabilidade.

Tabela 2 - Rendimento dos componentes fenológicos de culturas forrageiras colhidas no ponto de ensilagem

\begin{tabular}{lcccccc}
\hline Componente (\% MS) & Milho & Sorgo-sudão & Sorgo forrageiro & Girassol & Média & CV (\%) \\
\hline Espiga, ou panícula ou capítulo & $46,6 \mathrm{a}$ & $18,6 \mathrm{c}$ & $6,7 \mathrm{~d}$ & $35,7 \mathrm{~b}$ & 26,9 & 10,5 \\
Folha & $15,6 \mathrm{~b}$ & $11,3 \mathrm{~b}$ & $10,8 \mathrm{~b}$ & $23,9 \mathrm{a}$ & 15,4 & 20,0 \\
Colmo & $37,8 \mathrm{c}$ & $70,0 \mathrm{~b}$ & $82,3 \mathrm{a}$ & $40,3 \mathrm{c}$ & 57,6 & 8,2 \\
\hline
\end{tabular}

Médias seguidas pela mesma letra na mesma linha não diferem entre si pelo teste Tukey a 5\% de probabilidade. 
Conforme Mello et al. (2004), tão importante quanto a contribuição dos componentes estruturais da planta é a composição bromatológica da mesma. Assim, foram determinados os teores de MS, proteína bruta (PB), FDN, FDA, EE, celulose, hemicelulose, lignina, NIDN e NIDA.

Os teores de MS diferiram $(\mathrm{P}<0,05)$ entre as culturas (Tabela 3), pois foram maiores no sorgo-sudão, que foi semelhante ao milho e ao sorgo forrageiro, e menores no girassol. O conhecimento do teor de MS nas forragens é de grande importância, uma vez que as dietas dos animais são formuladas com base na MS, pois esses animais exigem quantidades específicas de nutrientes que se concentram na MS dos alimentos, para atender suas exigências de manutenção, crescimento, gestação e produção de leite. O teor de umidade ou conteúdo de MS de uma forragem é considerado o principal fator que determina a qualidade da silagem segundo McDonald et al. (1991).

O baixo teor de MS na cultura do girassol pode estar relacionado à variedade estudada, que, mesmo no ponto de ensilagem, apresentou alta umidade em determinada porção da planta, como o colmo, provavelmente em razão da maturidade fisiológica dos aquênios, ou seja, na fase reprodutiva "R9", as plantas do girassol apresentam a parte posterior dos capítulos amarelada e as brácteas com coloração amarelo-castanho.

Houve diferença $(\mathrm{P}<0,05)$ nos teores de $\mathrm{PB}$ entre as culturas avaliadas (Tabela 3). O teor de PB do girassol foi superior ao das demais culturas, e o do milho foi semelhante ao do sorgo forrageiro e do sorgo-sudão. O valor de PB na cultura do girassol neste trabalho foi inferior ao relatado por Mello et al. (2006), que, em experimento com híbridos de girassol em várias épocas de semeadura, encontraram médias de 8,7 a 14,8\% de PB. Flaresso et al. (2000), no entanto, encontraram teores de PB para milho variando entre 7,7 e 8,9\% e para o sorgo entre 6,3 e 7,7\%, valores esses superiores ao encontrado neste trabalho. Com exceção a cultura do girassol, as demais culturas apresentaram valores de PB baixos, ou seja, inferiores a 7\%, nível mínimo para um adequado funcionamento da microbiota do rúmen (Van Soest, 1994).

A maior concentração de extrato etéreo foi obtida na cultura do girassol, enquanto o milho, o sorgo forrageiro e o sorgo-sudão tiveram proporções bem menores e não diferiram ( $\mathrm{P}>0,05)$ entre si (Tabela 3$)$. Com relação ao alto teor de EE do girassol, o mesmo está relacionado ao fato de ser um vegetal que armazena sua energia no grão na forma de óleo. Forragens com maior teor de EE (gordura) tendem a ter valores mais altos de nutrientes digestíveis totais, pelo fato de a gordura fornecer 2,25 vezes mais energia do que os carboidratos. De acordo com o NRC (2001), na maioria das situações, o total de gordura na dieta para ruminantes não deve ultrapassar de 6 a 7\% na MS, em razão de poder determinar reduções na fermentação ruminal, na digestibilidade da fibra e na taxa de passagem. Dessa forma, o uso de forragens como a girassol, com os altos teores de $\mathrm{EE}$, em dietas para ruminantes tem limitações, o que indica possível necessidade de associação com outros alimentos volumosos.

Com relação aos teores de NIDN e NIDA (Tabela 3), não houve diferença $(\mathrm{P}>0,05)$ entre os teores NIDN entre as culturas. Contudo, houve diferença entre os teores de NIDA, a cultura do girassol foi superior às culturas do milho e do sorgo forrageiro, sendo o sorgo-sudão com teores semelhantes ao girassol e sorgo forrageiro. Van Soest (1994) sugeriu como normal o teor de NIDA aquele que se encontra dentro da amplitude de variação de 3 a 15\% do nitrogênio total. Todas as forragens do presente experimento apresentam valores dentro da amplitude estabelecida.

A determinação das frações fibrosas é muito importante na caracterização de forragens quanto ao seu valor nutritivo. Os componentes da parede celular das culturas (FDN, FDA,

Tabela 3 - Composição nutricional de culturas forrageiras colhidas no ponto de ensilagem

\begin{tabular}{|c|c|c|c|c|c|c|}
\hline Nutriente & Milho & Sorgo-sudão & Sorgo forrageiro & Girassol & Média & CV (\%) \\
\hline Matéria seca (\%) & $31,2 \mathrm{a}$ & $29,5 a b$ & $28,2 b$ & $19,0 \mathrm{c}$ & 27,0 & 5,2 \\
\hline Proteína bruta ${ }^{1}$ & $6,0 \mathrm{bc}$ & $6,8 \mathrm{~b}$ & $5,5 c$ & 8,0a & 6,6 & 8,5 \\
\hline Extrato etéreo ${ }^{1}$ & $4,1 \mathrm{~b}$ & $3,8 b$ & $3,8 b$ & $10,3 a$ & 4,1 & 23,9 \\
\hline $\mathrm{NIDN}^{2}$ & $19,7 a$ & $21,0 \mathrm{a}$ & $21,0 \mathrm{a}$ & $19,4 a$ & 20,3 & 10,0 \\
\hline NIDA $^{2}$ & $6,8 c$ & $8,9 a b$ & 8,0 bc & $10,3 a$ & 8,5 & 13,1 \\
\hline Fibra em detergente neutro ${ }^{1}$ & $60,0 \mathrm{ab}$ & $61,8 a$ & $56,9 b$ & $44,5 \mathrm{c}$ & 55,8 & 3,6 \\
\hline Fibra em detergente ácido ${ }^{1}$ & $39,2 b$ & $46,2 \mathrm{a}$ & $41,1 \mathrm{~b}$ & $40,9 b$ & 41.9 & 5,1 \\
\hline Celulose $^{1}$ & $34,8 b$ & $38,4 a$ & $35,8 a b$ & $33,4 b$ & 35,6 & 4,6 \\
\hline Hemicelulose ${ }^{1}$ & $20,7 a$ & $15,6 b$ & $15,7 \mathrm{~b}$ & $3,5 c$ & 13,9 & 11,5 \\
\hline Lignina $^{1}$ & $4,8 \mathrm{~b}$ & $7,6 a$ & $5,1 \mathrm{~b}$ & $8,5 a$ & 6,5 & 8,9 \\
\hline
\end{tabular}

${ }^{1}$ Porcentagem da matéria seca; ${ }^{2}$ Porcentagem do nitrogênio total.

NIDN: nitrogênio insolúvel em detergente neutro; NIDA: nitrogênio insolúvel em detergente ácido.

Médias seguidas por uma mesma letra em uma mesma linha não diferem entre si pelo teste Tukey a 5\% de probabilidade. 
celulose, hemicelulose e lignina) mostraram diferenças $(\mathrm{P}<0,05)$ entre as culturas (Tabela 3$)$.

Os percentuais de FDN observados variaram de 44,5 a $61,8 \%$. Foi verificado que a cultura do sorgo-sudão obteve a maior fração $(\mathrm{P}<0,05)$ de FDN diferindo estatisticamente do sorgo forrageiro e do girassol, que obtiveram o menor percentual. Já o teor de FDN do milho foi semelhante ao do sorgo forrageiro e do sorgo-sudão. Mello et al. (2006) em experimento com híbridos de girassol encontraram valores de 39,5 a 52,5\% de FDN superiores ao encontrado neste trabalho. Já Resende et al. (2003) encontraram valores de FDN variando de 43,45 a $60,98 \%$ e de 44,8 a $60,4 \%$ para as culturas de milho e de sorgo, respectivamente, valores esses semelhantes aos verificados neste trabalho. Vale ressaltar que a FDN é uma característica que está diretamente relacionada a velocidade de passagem do alimento pelo trato digestivo, e quanto menor o nível de FDN, maior o consumo de MS. Da mesma forma, o teor de FDN está diretamente relacionado a fatores como o ciclo da cultivar, temperaturas noturnas, teor de carboidratos solúveis, entre outros.

O percentual de FDA também diferiu $(\mathrm{P}<0,05)$ entre as culturas estudadas. O sorgo-sudão apresentou valores superiores ao do milho, do girassol e do sorgo forrageiro, que não diferiram entre si. Os valores obtidos são superiores aos encontrados por Resende et al. (2003), que encontraram valores de FDA variando de 22,66 a 31,06\% e de 26,5 a 40,6\%, para as culturas do milho e do sorgo, respectivamente. Já Mello et al. (2006) encontraram valor de 40,3\% de FDA para o girassol, resultado semelhante ao encontrado neste trabalho. A FDA está relacionada à digestibilidade da forragem, pois contém a maior proporção de lignina, que é a fração da fibra completamente indigestível, indicando, assim, sua indigestibilidade. Além disso, também é um indicador do valor energético do material, ou seja, quanto menor a FDA, maior será o valor energético da forragem.

A cultura do sorgo-sudão foi superior às do milho e do girassol e semelhante ao sorgo forrageiro quanto ao teor de celulose. O mais alto teor de celulose encontrado no sorgosudão está diretamente ligado à maior participação da fração FDN e FDA, pois a celulose é um importante componente dessas duas frações.

A maior concentração de hemicelulose foi observada para o milho e a menor, para o girassol (3,5\%), ao passo que o sorgo forrageiro e o sorgo-sudão tiveram valores semelhantes. Mello et al. (2004), trabalhando com silagens de milho, de sorgo e de girassol, também encontraram a menor fração de hemicelulose para a silagem de girassol.

O girassol e o sorgo-sudão tiveram as maiores frações de lignina, que foram superiores às do milho e do sorgo forrageiro. Os valores encontrados no girassol foram duas vezes maiores que os do milho, o que pode ser considerado fator negativo do ponto de vista nutricional, uma vez que a lignina é indigestível. Mello et al. (2006) observaram valores médios de 8,8 a 10,6\% de lignina em híbridos de girassol, valores superiores ao encontrado neste trabalho.

Os teores de nitrogênio, fósforo, potássio, cálcio, magnésio e sódio diferiram $(\mathrm{P}<0,05)$ entre as culturas (Tabela 4). O girassol apresentou as maiores concentrações de nitrogênio, cálcio, potássio e magnésio e seu teor de sódio foi semelhante ao do sorgo forrageiro e superior ao do milho e do sorgo-sudão. As concentrações de potássio e magnésio no milho foram menores que no sorgo forrageiro. O maior teor de fósforo foi encontrado no sorgo-sudão, seguido do girassol, cujo valor foi superior ao do milho e ao do sorgo forrageiro. Os minerais cujas concentrações foram superiores a $1 \%$ foram o nitrogênio e potássio, o que evidencia a importância da correta adubação de base desses elementos quando se trabalha com culturas destinadas à ensilagem.

Dados na literatura sobre a composição mineral dessas culturas são escassos. Em híbridos de girassol, Mello et al. (2006) observaram teores mais elevados que os deste trabalho para fósforo $(0,30$ a $0,46 \%)$ e magnésio $(0,60$ a $0,72 \%)$; valores semelhantes para cálcio $(0,76$ a $0,84 \%)$ e potássio (1,5 a 2,65\%); e valor inferior para sódio $(0,01$ a 0,02\%). Em híbrido de sorgo submetido a dois cortes, Mello et al. (2003) encontraram teores superiores de fósforo (entre 0,16 e $0,24 \%)$ e magnésio $(0,30$ a $0,44 \%)$ e valores semelhantes aos deste trabalho para cálcio (0,21 e 0,29\%) e

Tabela 4 - Teores de minerais em forrageiras colhidas no ponto de ensilagem

\begin{tabular}{|c|c|c|c|c|c|c|}
\hline Nutriente (\% MS) & Milho & Sorgo-sudão & Sorgo forrageiro & Girassol & Média & CV (\%) \\
\hline Nitrogênio & $0,95 b c$ & $1,10 \mathrm{~b}$ & $0,95 b c$ & $1,27 \mathrm{a}$ & 1,06 & 8,5 \\
\hline Cálcio & $0,13 b$ & $0,18 b$ & $0,18 b$ & $0,85 a$ & 0,33 & 10,5 \\
\hline Fósforo & $0,15 c$ & $0,23 a$ & $0,12 \mathrm{c}$ & $0,20 b$ & 0,18 & 9,7 \\
\hline Potássio & $0,98 \mathrm{c}$ & $1,15 b c$ & $1,26 b$ & $2,38 a$ & 1,44 & 8,0 \\
\hline Magnésio & $0,12 \mathrm{c}$ & $0,15 b c$ & $0,20 \mathrm{~b}$ & $0,34 \mathrm{a}$ & 0,20 & 20,4 \\
\hline Sódio & $0,05 b$ & $0,05 b$ & $0,09 \mathrm{ab}$ & $0,11 \mathrm{a}$ & 0,08 & 36,3 \\
\hline
\end{tabular}

Médias seguidas pela mesma letra na mesma linha não diferem entre si pelo teste Tukey a 5\% de probabilidade. 
magnésio (1,75 e 2,85\%). Mello et al. (2004), trabalhando com silagens dessas culturas, encontraram teores de cálcio, fósforo, potássio e magnésio mais elevados para silagem de girassol em relação às de milho e sorgo.

De acordo com McDowell (2001), a deficiência de minerais provoca diversas doenças nos animais, como hipocalcemia (cálcio), hipomagnesemia (magnésio), predisposição à hipomagnesemia (potássio), raquitismo e osteomalácia (cálcio e fósforo). Esse autor mencionou ainda que as necessidades de minerais para vacas em lactação seriam de: 0,43 a 0,77\% de cálcio; 0,25 a 0,49\% de fósforo; 0,20 a $0,25 \%$ de magnésio e 0,90 a $1,00 \%$ de potássio. Portanto, apenas a forragem de girassol seria eficiente no fornecimento de cálcio e magnésio. As exigências de fósforo, no entanto, não seriam atendidas por nenhuma forragem, enquanto as de potássio são atendidas por qualquer forragem.

Houve diferença $(\mathrm{P}<0,05)$ entre as culturas quanto à extração de cálcio, fósforo, potássio e magnésio (Tabela 5). A maior extração de cálcio e potássio foi observada na cultura de girassol, enquanto o sorgo-sudão apresentou a

Tabela 5 - Extração de nutrientes de forrageiras colhidas no ponto de ensilagem

\begin{tabular}{|c|c|c|c|c|c|c|}
\hline Nutriente (kg/ha) & Milho & Sorgo-sudão & Sorgo forrageiro & Girassol & Média & CV (\%) \\
\hline Nitrogênio & $199,3 a$ & $216,9 a$ & $204,1 \mathrm{a}$ & $204,3 a$ & 206,2 & 12,9 \\
\hline Cálcio & $28,9 b$ & $34,9 \mathrm{~b}$ & $42,0 \mathrm{~b}$ & $136,9 a$ & 60,6 & 13,6 \\
\hline Fósforo & $33,1 b$ & $46,1 \mathrm{a}$ & $29,7 b$ & $32,0 \mathrm{~b}$ & 35,2 & 16,3 \\
\hline Magnésio & $26,5 b$ & $30,9 b$ & $47,2 \mathrm{a}$ & $54,5 a$ & 39,8 & 20,4 \\
\hline Sódio & $11,2 \mathrm{a}$ & $10,8 a$ & $23,2 \mathrm{a}$ & $18,9 a$ & 16,0 & 45,0 \\
\hline
\end{tabular}

Médias seguidas pela mesma letra na mesma linha não diferem entre si pelo teste Tukey a 5\% de probabilidade.

maior extração de fósforo e milho, o sorgo forrageiro e o girassol tiveram extrações semelhantes desse mineral. A extração de magnésio foi maior nas culturas de girassol e sorgo forrageiro. Não houve diferença na extração de nitrogênio e sódio entre as culturas.

\section{Conclusões}

As culturas de milho e sorgo forrageiro apresentam maior produtividade de matéria seca por área em comparação à de girassol. A cultura de sorgo-sudão têm maior concentração de fibra em relação às demais e possui, portanto, menor valor nutritivo. Em termos gerais, a extração de minerais é maior na cultura de girassol, cujas concentrações de extrato etéreo e lignina também são mais elevadas, fatores de restrição na alimentação animal. O milho, entre todas as culturas estudadas, apresenta melhor proporção de componentes desejáveis para ensilagem (espiga em relação a colmo).

\section{Referências}

CAPPELLE, E.R.; VALADARES FILHO, S.C.; SILVA, J.F.C. et al. Estimativas do valor energético a partir de características químicas e bromatológicas dos alimentos. Revista Brasileira de Zootecnia, v.30, n.6, p.1837-1856, 2001.

CARVALHO, L.F.; MEDEIROS FILHO, S.; ROSSETTI, A.G. et al. Condicionamento osmótico em sementes de sorgo. Revista Brasileira de Sementes, v.22, n.1, p.185-192, 2000

CASTRO, C.; OLIVEIRA F.A.; VERONESI, C.O. et al. Acúmulo de matéria seca, exportação e ciclagem de nutrientes pelo girassol.
In: REUNIÃO NACIONAL DE PESQUISA DE GIRASSOL, 16. 2005, Londrina. Anais... Londrina: EMBRAPA CNPSO, 2005, p.29-31.

FERNANDES, F.E.P; GARCIA, R., PIRES, A.J.V. et al. Ensilagem de sorgo forrageiro com adição de ureia em dois períodos de armazenamento. Revista Brasileira de Zootecnia, v.38, n.11, p.2111-2115, 2009.

FLARESSO, J.A.; GROSS, C.D.; ALMEIDA, E.X. Cultivares de milho (Zea mays L.) e sorgo (Sorghum bicolor L. Moench) para ensilagem no Alto Vale do Itajaí, Santa Catarina. Revista Brasileira de Zootecnia, v.29, n.6, p.1608-1615, 2000.

FONSECA, A.H.; VON PINHO, R.G.; PEREIRA, M.N. et al. Desempenho de cultivares de milho em relação às características agronômicas, químicas e degradabilidade da silagem. Revista Ceres, v.49, n.282, p.109-122, 2002.

HENRIQUE, W.; ANDRADE, J.B. Silagem de milho, sorgo, girassol e suas consorciações. I. produção e composição. In: REUNIÃO ANUAL DA SOCIEDADE BRASILEIRA DE ZOOTECNIA, 34. 1997, Juiz de Fora. Anais... Juiz de Fora: SBZ, 1997. p.196-198.

LEITE, R.M.V.B.C.; BRIGHENTI, A.M.; CASTRO, C. (Ed.). Girassol no Brasil. Londrina: Embrapa Soja, 2005, 641p.

LEMPP, B.; MORAIS, M.G.; SOUZA, L.C.F. Produção de milho em cultivo exclusivo ou consorciado com soja e qualidade de suas silagens. Arquivo Brasileiro de Medicina Veterinária e Zootecnia, v.52, n.3, p.243-249, 2000.

MAGALHÃES, P.C.; DURÃES, F.O.M. Ecofisiologia da produção de sorgo. Sete Lagoas: EMBRAPA Milho e Sorgo, 2003. 4p. (Comunicado Técnico, 87).

MAGALHÃES, P.C.; DURAES, F.O.M.; SCHAFFERT, R.E. Fisiologia da planta de sorgo. Sete Lagoas: Embrapa Milho e Sorgo, 2000. 46p. (Circular Técnica, 3).

McDONALD, P.; HeNDERSON, A.R.; HeRON, S. The biochemistry of silage. Marlow: Chalcombe Publications, 1991. 340p.

McDOWELL, L.R. Recent advances in minerals and vitamins on nutrition of lactating cows. In: SIMPÓSIO INTERNACIONAL EM BOVINOCULTURA DE LEITE: NOVOS CONCEITOS EM NUTRIÇÃO, Lavras. Anais... Lavras: Universidade Federal de Lavras, 2001. v.2, p.51-76. 
MELLO, R.; NÖRNBERG, J.L.; RESTLE, J. et al. Características fenológicas, produtivas e qualitativas de híbridos de girassol em diferentes épocas de semeadura para produção de silagem. Revista Brasileira de Zootecnia, v.35, n.3, p.672-682, 2006.

MELLO, R.; NORNBERG, J.L.; ROCHA, M.G. et al. Análise produtiva e qualitativa de um hibrido de sorgo interespecífico submetido a dois cortes. Revista Brasileira de Milho e Sorgo, v.2, n.1, p.20-33, 2003.

MELLO, R.; NÖRNBERG, J.L.; ROCHA, M.G. Potencial produtivo e qualitativo de híbridos de milho, sorgo e girassol para ensilagem. Revista Brasileira de Agrociência, v.10, n.1, p.87-95, 2004.

NATIONAL RESEARCH COUNCIL - NRC. Nutrient requirements of dairy cattle. 7.ed. Washington: National Academy Press, 2001. 362p.

NEUMANN, M.; RESTLE, J.; FILHO, D.C.A. et al. Avaliação do valor nutritivo da planta e da silagem de diferentes híbridos de sorgo (Sorghumbicolor (L.) Moench.). Revista Brasileira de Zootecnia, v.31, n.1, p.293-301, 2002.

QUEIROZ, D.S.; GOMIDE, J.A.; MARIA, J. Avaliação da folha e do colmo de topo e base de perfilhos de três gramíneas forrageiras. 1. Anatomia. Revista Brasileira de Zootecnia, v.29, n.1, p.61-68, 2000.
RESENDE, J.A.; PEREIRA, M.N.; VON PINHO, G.R. et al. Ruminal silage degradability and productivity of forage and grain-type sorghum cultivars. Scientia Agricola, v.60, n.3, p.457-463, 2003.

RIBEIRO JR., J.I. SAEG Sistema para análises estatísticas e genética, versão 8.0. Viçosa: Fundação Arthur Bernardes, 2001. 301p.

SILVA, D.J.; QUEIROZ, C. Análise de alimentos (Métodos químicos e biológicos). Viçosa, MG: Universidade Federal de Viçosa, 2002. 235p.

VAN SOEST, P.J. Nutritional ecology of the ruminant. 2.ed. Ithaca, New York : Cornell University, 1994. 476p.

VASCONCELOS, R.C.; VON PINHO, R.G.; REZENDE, A.V. et al. Efeito da altura de corte das plantas na produtividade de matéria seca e em características bromatológicas da forragem de milho. Ciência e Agrotecnologia, v.29, n.6, p.1139-1145, 2005.

VILLELA, T.E.A.; VON PINHO, G.R.; GOMES, M.S. et al. Conseqüências do atraso na época de semeadura e de ensilagem em características agronômicas do milho. Ciência e Agrotecnologia, v.27, n.2, p.271-277, 2003.

VON PINHO, G.R.; VASCONCELOS, R.C.; BORGES, I.D. et al. Influência da altura de corte das nas características agronômicas e valor nutritivo das silagens de milho e de diferentes tipos de sorgo. Revista Brasileira de Milho e Sorgo, v.5, n.2, p.266-279, 2006. 